\title{
Are Facial Displays Social? Situational Influences in the Attribution of Emotion to Facial Expressions
}

\author{
José-Miguel Fernández-Dols's, Pilar Carrera', and James A. Russell² \\ ${ }^{1}$ Universidad Autónoma de Madrid \\ ${ }^{2}$ Boston College
}

\begin{abstract}
Observers are remarkably consistent in attributing particular emotions to particular facial expressions, at least in Western societies. Here, we suggest that this consistency is an instance of the fundamental attribution error. We therefore hypothesized that a small variation in the procedure of the recognition study, which emphasizes situational information, would change the participants' attributions. In two studies, participants were asked to judge whether a prototypical "emotional facial expression" was more plausibly associated with a social-communicative situation (one involving communication to another person) or with an equally emotional but nonsocial, situation. Participants were found more likely to associate each facial display with the social than with the nonsocial situation. This result was found across all emotions presented (happiness, fear, disgust, anger, and sadness) and for both Spanish and Canadian participants.

Key words: facial expression, recognition of emotion, emotion, emotion expression
\end{abstract}

La atribución de emociones a determinadas expresiones faciales es un fenómeno notablemente robusto, al menos en las sociedades occidentales. En este artículo proponemos que la consistencia de dichas atribuciones es un caso de error fundamental de atribución. Si nuestra hipótessis es correcta, pequeñas variaciones en el procedimiento de los estudios típicos sobre reconocimiento de emociones (dando un mayor énfasis a la información situacional) cambiarán de manera sustantiva la forma en la que los perceptores atribuyen emociones a las expresiones faciales. Para comprobar dicha hipótesis hemos llevado a cabo dos estudios en los que los participantes deben decidir si una expresión prototípica de emoción se asocia con una situación social (que implica comunicación con otra persona) o con una situación emocional pero no social. Nuestros sujetos asociaron la expresión facial con la situación social, en lugar de la no social. Los resultados fueron los mismos para todas las emociones consideradas (alegría, miedo, asco, enfado y tristeza) y tanto para sujetos españoles como para los canadienses. Palabras clave: expresión facial, reconocimiento de emociones, emoción, expresión emocional

We thank Lara Weick and Lisa Wong for their excellent work on this study.

Correspondence concerning this article should be addressed to José-Miguel Fennández-Dols, Facultad de Psicologia. Universidad Autónoma de Madrid. Ciudad Universitaria de Cantoblanco. 28049 Madrid (Spain). E-mail: jose.dols@uam.es 


\section{Are Facial Displays Social?}

The phrase "facial expression of emotion" captures the common-sense idea that certain facial movements are closely tied with emotion. Influential theories in the psychology of emotion maintain this tie by assuming that facial displays are a spontaneous result of, part of, or precursor to the occurrence of emotion (e.g., Buck, 1984; Ekman, 1972). According to such views, human beings universally recognize the emotion signalled by the facial display. (For a review of some alternative views, see Russell, Bachorowski, \& Fernández-Dols, in press).

Consensus on the "recognition" (attribution) of emotion from a few facial expressions is well documented with Western samples, but it is far from being as consistent and extensive in non-Western, especially illiterate societies (see Russell \& Fernández-Dols, 1997). Figure 1 provides a summary of relevant results from cross-cultural judgment studies. The figures given are average "recognition scores" (the percentage of participants who select the predicted emotion) for six "basic expressions" (happiness, surprise, anger, sadness, fear, and disgust). The first bar comes from Western literate societies; the magnitude is impressive. The second bar comes from non-Western literate societies; this second score is reliably lower than the first but still high. The third bar comes from more isolated, illiterate samples; these participants attributed happiness to smiles but yielded noticeably lower recognition scores with all other expressions (Russell, 1994; see also Elfenbein \& Ambady, 2002).

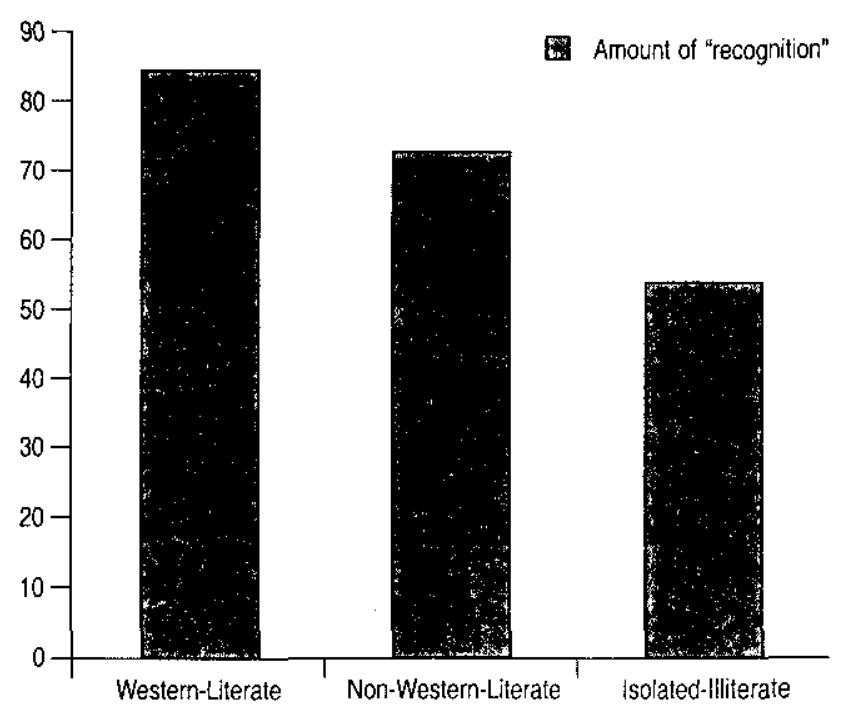

Figure l. Average recognition scores for six facial expressions of emotion (happiness, surprise, anger, sadness, fear, and disgust) across Western literate, non-Western literate, and isolated illiterate cultures. Recognition scores are proportional to the amount of Western influence (adapted from Russell \& Fernández-Dols, 1997).
In this article, we suggest that receivers' remarkable consistency when attributing a particular emotion to a particular expression is an example of the fundamental attribution error: People, particularly those from Western cultures, underestimate situational influences, while inferring stable abilities, attitudes, and personality traits that lead them to expect "consistency in behavior or outcomes across widely disparate situations and contexts" (Ross, 1977, p. 184).

Indeed the design of the recognition studies encourages or presupposes the fundamental attribution error by ignoring the context in which the facial display takes place. People guide their attributions about facial expression and emotion by ideal, simplified, and consistent representations of situations in which they lump together emotional experience and facial behavior that actually happened at different times (Fernández-Dols, 1999). For example, affiliative smiling and happiness are usually observed in the same interactive situations, which leads people to believe that smiling is a sign of happiness across all kinds of situations and contexts.

In the experiments reponted here, we test whether people are capable of differentiating the actual immediate experience of emotion from the surrounding interaction.

\section{When are Facial Displays Thought to Occur?}

Fridlund (1994) suggested that the social motive, rather than the emotion, elicited by the presence of another person would be the most powerful determinant of the occurrence of a facial display. In contrast, on the standard emotional account of facial displays, the presence of another person is secondary, in that it might, but need not, invoke a "display rule" (Ekman, 1972; Klineberg, 1940), thereby inhibiting, exaggerating, or masking the spontaneous facial display.

A simple variation of the usual procedure in recognition studies will allow us to test whether, when provided with situational information, people link "expressions of emotion" to the experience of emotion ("immediate experience" condition) or rather to other processes such as the communication of social motives.

Participants were shown two photographs of the same person: one with a prototypical "emotional" expression and one without ("neutral"). Participants were also given two sentences, both expressing the corresponding emotion content. In one sentence (nonsocial condition), the protagonist was thinking the sentence. In the other (the social-communicative condition), the protagonist was speaking the sentence. For instance, in one trial concerning happiness, the facial expression was a smile and the sentences concerned winning the lottery. In the nonsocial condition, the protagonist thought, "We have won the prize!" In the social condition, the protagonist spoke to someone, 
saying "John, we have won the prize!" The participant"s task was to pair each situation with a photograph.

If the emotion-based account of facial displays is correct, participants would consider two alternatives: (a) If the social situation suggested a display rule, that is, the inhibition of the expression, the participant would associate the social situation with the neutral face. The nonsocial situation would then be paired with the intense, full expression; (b) If the participant did not perceive any reason for inhibiting the facial display in the situation, then the choice would be random. Overall, then, $50 \%$ or fewer subjects would pair the facial display with the social situation, $50 \%$ or more would pair it with the nonsocial situation. On the other hand, if our hypothesis is correct, participants' choices should be ruled by an opposite set of assumptions. Facial displays would be judged as communicative behavior and most participants would associate the facial display with the social situation.

\section{Experiment 1}

\section{Method}

\section{Participants}

Participants were 20 adults, of whom half were men, half womerl, and all students of the University of British Columbia (Canada). Participants were selected from the volunteer list of first and second year psychology students, and given credit toward their course marks.

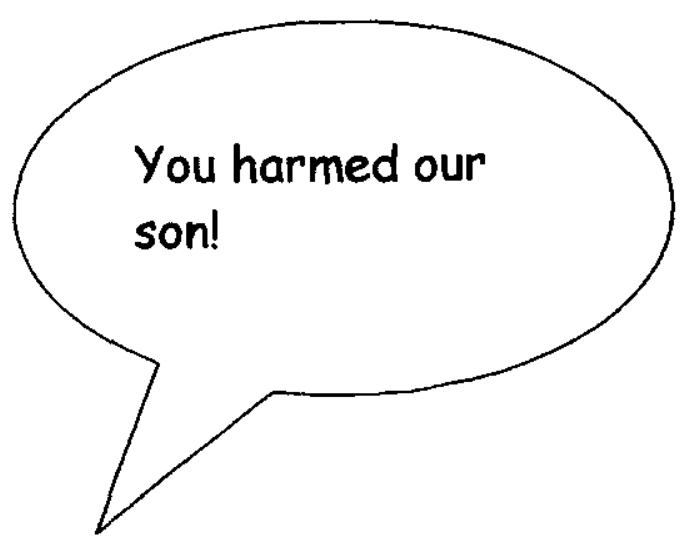

\section{Social Condition}

\section{Facial expressions}

There were 11 pairs of photographs. Each pair consisted of the same actor with a neutral and with one prototypical "expression of emotion." There were two each of fear, happiness, sadness, and disgust, and three of anger. One expression of fear came from Camras' collection (Camras, Grow, \& Ribordy, 1983), one of happiness from Russell's collection (Russell \& Bullock, 1985), and the rest from Ekman and Friesen's set (Ekman \& Friesen, 1976).

\section{Sentences}

There were 11 pairs of sentences (two each of fear, happiness, sadness, and disgust, and three of anger), with both sentences in each pair describing the same emotional content. In one sentence, the person was thinking about the situation (e.g., "So this means that this food is spoiled!"), whereas in the other sentence, the person was speaking to someone about it (e.g., "Look at this food. It's spoiled!"). To emphasize the difference between the two conditions, we borrowed a convention from cartoons, as shown in Figure 2. The social/spoken versions of the 11 sentences are given in Table 1.

It might be argued that even though the content of the sentences was the same in the social and the nonsocial situations, the social situations are inherently more emotional. If so, participants here simply associated the facial displays with the more intense emotional experience. For some sentences, the social version indeed might be somewhat more

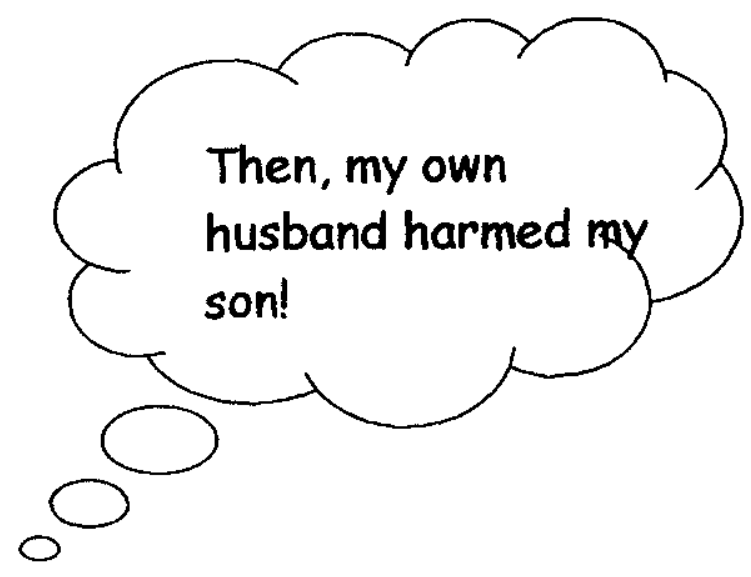

Figure 2. Sentence pait offered to participants in Trial 3 (Anger), Study 1.

\footnotetext{
I Display rules allow not only inhibition but also masking or exaggeration. These possibilities were not considered to be among the participants' choices here.
} 
emotional; for instance, "You harmed our son!" implies direct confrontation, whereas "Then, my own husband harmed my son!" does not. Nevertheless, the opposite is probably the case for other sentences. For instance, discovering that someone is hidden in the kitchen or being followed by a strange man would likely create more fear if alone.

\section{Procedure}

Subjects were tested individually. There were 11 trials. Each trial concerned one emotion. The experimenter presented the first pair of photographs and corresponding pair of sentences. The participant was asked to pair faces and sentences in the "more plausible" or "more natural" way. The experimenter pointed out that one sentence was thought, the other spoken, and that there were no right or wrong answers. A separate random order of the 11 trials was created for each participant.

\section{Results}

Table 1 shows the percentage of participants associating the facial displays with the spoken sentence, that is, the social situation. Overall, facial expression was associated with the spoken sentence on 178 of the 220 trials $(80.9 \%)$. For each type of emotion, a majority of participants (from $75 \%$ to $92.5 \%$ ) placed the facial expression with the spoken version of the sentence. A Wilcoxon signed ranks test, comparing the magnitude and direction of the differences within pairs of possible choices for the 11 trials (facial expression associated with spoken sentence vs. neutral face associated with the spoken sentence) was highly significant $(z=2.94, p<.003)$. Moreover, every participant individually showed this pattern; across the 11 trials, the median number of spoken sentences associated with emotion expression was 9, with a range of 6 to 11 .

\section{Experiment 2}

Experiment 2 was a replication of Experiment 1 with a different set of facial expressions (Matsumoto \& Ekman, 1988) and a sample that included Canadian and Spanish participants.

\section{Method}

The method was identical to that of Experiment 1, with the following exceptions. Participants were 40 adults, 20 Spanish and 20 Canadian first- and second-year psychology students, of whom half were men, half women. There were 10 trials instead of 11 , and the content of several of the sentences was modified slightly, as shown in Table 2 . Photographs were of 10 different models (all Western and female) taken from Matsumoto and Ekman (1988).

\section{Results}

Table 2 shows the percentage of participants associating the facial display with the spoken sentence (social situation). Overall, the results were similar to those obtained in Study 1. Facial displays were associated with a social situation on 288 of the 400 trials $(72 \%)$. For each type of emotion, a majority of participants (from $62.5 \%$ to $86.2 \%$ ) placed the facial display with the spoken version of the sentence. A Wilcoxon signed ranks test, comparing the magnitude and direction of the differences within pairs of possible choices for the 10 trials (facial expression associated with spoken sentence vs. neutral face associated with the spoken sentence) was highly significant $(z=2.66, p<.008$, for the whole sample; $z=2.68, p<.007$, for the Canadian subsample; and $z=2.43, p<.015$, for the Spanish subsample). Over the 10 trials, the median number of spoken sentences

Table 1

Percentage of Subjects Associating Facial Displays with a Spoken. Social Situation

\begin{tabular}{ll}
\hline Emotion & Spoken Version of Sentence \\
\hline Happiness & "John, we have won the prize!" \\
& "John, our son will come back from the war tomorrow!" \\
"Ynger & "You harmed our son!" \\
& "Peter, you cheated me!" \\
& "Lionel, you have made me miss the bus!" \\
& "John, I miss my son so much!" \\
Sadness & "Sweetheart, I have not passed the exam!" \\
& "Please, help me! There is somebody hidden in my kitchen!" \\
Fear & "John, please help me! A strange man is following me!" \\
& "Look at this dead rat!" \\
Disgust & "Look at this food, it"s spoiled!" \\
\end{tabular}

Note. Canadian sample, $N=20$. 
Table 2

Percentage of Subjects Associating Facial Displays with a Spoken, Social Situation

\begin{tabular}{llcc}
\hline Emotion & Spoken Version of Sentence & Spanish \% & Canadian \% \\
\hline Happiness & "John, we have won the prize!" & 100 & 85 \\
& "John, our brother will come back from the war tomorrow!" & 85 & 75 \\
Anger & "You, my own husband, are playing a trick on me!" & 60 & 60 \\
& "Lionel, you have made me miss the bus!" & 80 & 85 \\
Sadness & "John, I miss my son so much!" & 40 & 70 \\
& "Sweetheart, I have not passed the exam!" & 90 & 65 \\
Fear & "Please, help me! There is somebody hidden in my kitchen!" & 65 & 75 \\
& "John, please help me! A strange man is following me!" & 65 & 50 \\
Disgust & "Look at this dead rat!" & 50 & 60 \\
\end{tabular}

Note. Spanish sample, $N=20$. Canadian sample, $N=20$.

associated with facial displays was 7 , with a range of 6 to 10 for the Canadians, and 6.5 for the Spaniards, with a range of 3 to 10 . All in all, nationality of participants did not change the basic pattern of responses already described.

An alternative explanation to these results might be as follows: (a) Participants paired the intense facial display with the spoken sentence because the other possible pairing (display plus thought sentence) seemed somehow unnatural, or (b) participants paired the neutral display with the thought sentence because the combination of neutral expression with the spoken sentence seemed somehow unnatural.

To explore these possibilities, a small study was conducted. The 40 possible combinations of each pair of facial displays (neutral plus expressive) and the sentences (thought plus spoken) used in Experiment 2 were formed. Four groups of 10 combinations each were formed so as to avoid repetitions of either facial display or sentence. Forty participants were assigned to one of the four independent groups. (Each group therefore judged 10 different combinations.) For all comparisons of interest, the data were therefore between-subjects. Their task consisted of judging "how natural" was each combination on a scale from 0 (maximally umatural) to 10 (maximally natural).

No combination of the facial display with the thought sentence was considered significantly less natural than that display with the spoken sentence. In three cases, however, the combination of the neutral face with the spoken sentence was considered significantly less natural than the combination of the neutral face with the thought sentence: the first, fifth, and sixth sentences $(t=-2.28, p<.05 ; t=2.39, p<.05 ; t=-3.24$, $p<.01$, respectively) listed in Table 2 . The results of Experiment 2 were re-analyzed with these three sentences omitted. A Wilcoxon signed ranks test, comparing the magnitude and direction of the differences within pairs of possible judgments for the seven trials (facial expression associated with spoken sentence vs. neutral face associated with the spoken sentence) was highly significant $(z=2.36, p<.018)$. Facial expression was found to be associated with the social situation.

\section{Conclusions}

In the studies reported here, we have found that participants were able to differentiate the actual immediate experience of emotion from the surrounding interaction. A simple manipulation, emphasizing situational information, allowed us to show that people do not necessarily link expressions of emotion to the experience of emotion (immediate experience condition), but rather to other actions. The usual "recognition" studies do not take into account these other actions (e.g., communicative actions). Thus, subjects are forced into making raw, large-scale correlations between facial behavior and emotion (Fernández-Dols, 1999).

Some additional evidence supports these findings. Carroll and Russell (1996) carried out a study on recognition of emotion in which they provided participants with some situational information that allowed them to explain the physical features of the prototypical expressions of emotion (e.g., staring eyes, furrowed eyebrows, lips pressed tightly together in anger) by nonemotional actions included in the situation (e.g., a person peering at a distant message and having difficulty in making a decision about it). They found that people judged facial expressions in terms of the situation instead of the expected emotion, reversing the usual trend in recognition studies. For example, what is usually labeled an "expression of anger" became an "expression of puzzlement" when it was displaying physical actions that were plausible for nonemotional reasons in a given context. People could "recognize" that a "universal expression" is not necessarily related to an emotion. Some salient situational hints helped them to overcome the bias that usually leads them to "recognize" universal expressions.

Therefore, our results encourage pursuit of the idea that people "recognition" of emotion is an instance of attributional error. 


\section{References}

Buck, R. (1984). The communication of emotion. New York: Guilford Press.

Camras, L.A., Grow, V.G., \& Ribordy, S.C. (1983). Recognition of emotional expression by abused children. Joumal of Clinical Child Psychology, 12, 325-328.

Carroll, J.M., \& Russell, J.A. (1996). Do facial expressions signal specific emotions? Judging the face in context. Journal of Personality and Social Psychology, 70, 205-218.

Ekman, P. (1972). Universals and cultural differences in facial expressions of emotions. In J, Cole (Ed.), Nebraska Symposium on Motivation: Vol. 19. 1971 (pp. 207-283). Lincoln, NE: University of Nebraska Press.

Ekman, P., \& Friesen, W.V. (1976). Pictures of facial affect. Palo Alto, CA: Consulting Psychologists Press.

Elfenbein, H.A., \& Ambady, N. (2002). On the universality and cultural specificity of emotion recognition : A meta-analysis. Psychological Bulletin, 128, 203-235.

Fernández-Dols, J.M. (1999). Facial expression and emotion: A situationist view. In P. Philippot, R.S. Feldman, \& E.J. Coats (Eds), The social context of nonverbal behavior (pp. 242-261). New York: Cambridge University Press.

Fridlund, A.J. (1994). Human focial expression: An evolutionary view. New York: Academic Press.
Klineberg, O. (1940). Social psychology. New York: Holt.

Matsumoto, D., \& Ekman, P. (1988), Japanese and Caucasian facial expressions of enotion (JACFFE). Slide and brochure. San Francisco, CA: San Francisco State University. (Available from the first author.)

Ross, L. (1977). The intuitive psychologist and his shortcomings: Distortions in the attribution process. Advances in Experimental Social Psychology, 10, 174-221.

Russell, J.A. (1994). Is there universal recognition of emotion from facial expressions? A review of cross-cultural studies. Psychological Bulletin, 110, 426-450.

Russell, J.A., Bachorowski, J-A., \& Femández-Dols, J.M. (in press). Facial and vocal expressions of emotion. Annual Review of Psychology.

Russell, J.A., \& Bullock, M. (1985). Multidimensional scaling of emotional facial expressions: Similarity from preschoolers to adults. Joumal of Personality and Social Psychology, 48, 12901298.

Russell J.A., \& Fernández-Dols, J.M. (1997). What does a facial expression mean? In J.A. Russell \& J.M. Fernández-Dols (Eds.), The psychology of facial expression (pp. 3-30). New York: Cambridge University Press.

Received September 2, 2002 Revision received September 16, 2002 Accepted September 30, 2002 